\title{
Absence of musculocutaneous nerve and accessory head of biceps brachii: a case report
}

\author{
L. Arora, R. Dhingra \\ Department of Anatomy, AlIMS, Ansari Nagar, Delhi.
}

Address for correspondence: Latika Arora, Department of Anatomy, AlIMS, Ansari Nagar, Delhi

\section{ABSTRACT}

During dissection of a 55-year-old female cadaver, we observed that three nerve roots contributed to the formation of Median nerve in her right upper limb. Along with this variation, absence of Musculocutaneous nerve was noticed. The muscles of front of arm i.e. Biceps Brachii, Brachialis and Coracobrachialis received their nerve supply from Median nerve. The Lateral cutaneous nerve of forearm was derived from Median nerve. Also an accessory head of Biceps Brachii muscle was present in the right arm of the same cadaver. It is extremely important to be aware of these variations while planning a surgery in the region of axilla or arm as these nerves are more liable to be injured during operations.

\section{KEY WORDS}

Musculocutaneous nerve, Third head of biceps

\section{INTRODUCTION}

re he Brachial plexus is formed by the lower four cervical ventral rami with a variable contribution from $\mathrm{C} 4$ and T2. Variations in the formation and branching of brachial plexus are common and have been reported by several investigators. ${ }^{1-3}$ Normally the Musculocutaneous nerve arises from lateral cord of brachial plexus but is has frequent variations. The nerve may be doubled, unusually short or even absent. According to Tountas and Bergaman (1993), ${ }^{4}$ the Musculocutaneous nerve arises from the lateral cord in $90.5 \%$, from lateral and posterior cord in $4 \%$, from medial cord in $2 \%$ and as two separate bundles from the medial and lateral cords in $1.4 \%$. Willams et al (1989) ${ }^{5}$ stated that some fibers of the median nerve may run in Musulocutaneous nerve leaving it to join their main trunk. The reverse occurs less frequently where median nerve sends a branch to Musculocutaneous nerve. We describe here the exact topography of this variation and discuss its morphological and clinical significance.

\section{MATERIAL AND METHODS}

The study was conducted on 100 cadavers dissected by the undergraduate students of All India Institute of Medical Sciences, New Delhi. The cadavers were embalmed using $4 \%$ formaldehyde solution and preserved in weak formalin solution. The brachial plexus was dissected according to the guidelines of Cunningham's manual. During the dissection the variation from normal pattern was noted and photographed.

\section{OBSERVATIONS}

The origin and course of Musculocutaneous and Median nerve were seen to be different from normal in one cadaver: In the right upper limb of a female cadaver the Median nerve had three roots and the Musculocutaneous nerve was 
absent [Figure 1]. The Median nerve innervated the arm muscles i.e. Biceps brachii, Brachialis and Coracobrachialis. During dissection of front of the right arm we also observed an accessory head of Biceps Brachii muscle [Figure 2]. The long and short heads of Biceps had their normal origin, the accessory head originated from the anteromedial surface of the humerus. The accessory head was present in the sulcus between long and short heads and joined the two heads for insertion into radial tuberosity. Out of 100 cases we found musculocutaneous nerve absent in 15 cases, third head of biceps in 3 cases, the rest had normal anatomy.

\section{DISCUSSION}

In the past many variations have been described regarding the course of musculocutaneous and median nerves. Le Minor (1992) ${ }^{6}$ described five types of variations [Figure 3] Type 1: There is no communication between the Median and Musculocutaneous nerve.

Type 2: The fibers of medial root of median nerve pass through the Musculocutaneous nerve and join the Median nerve in the middle of the arm.

Type3: The lateral root fibers of medial root of median nerve pass through the Musculocutaneous nerve and after some distance, leave it to form the root of the Median nerve. Type 4: The Musculocutaneous fibres join the lateral root of the Median nerve and after some distance the Musculocutaneous arise from the median nerve.

Type 5: The Musculocutaneous nerve is absent and the entire fibres of Musculocutaneous pass through lateral root and fibres to the muscles supplied by Musculocutaneous nerve branch out directly from Median nerve.

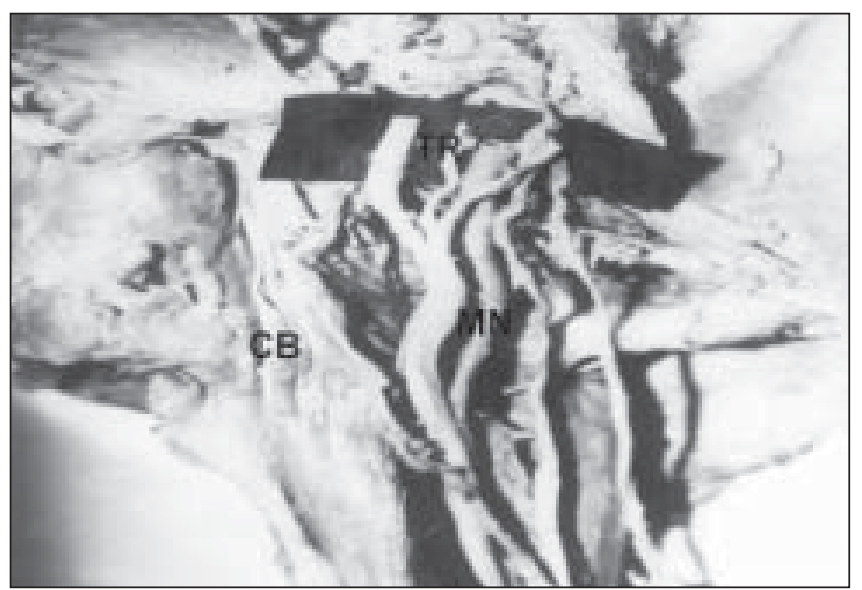

Figure 1: Photograph of the dissected right upper arm showing the lateral and medial roots of median nerve (MN). Note the third root (TR) joining the median nerve (MN). Absence of musculocutaneous nerve. Brachial artery (BR) and corachobrachialis muscle (CB) are also seen

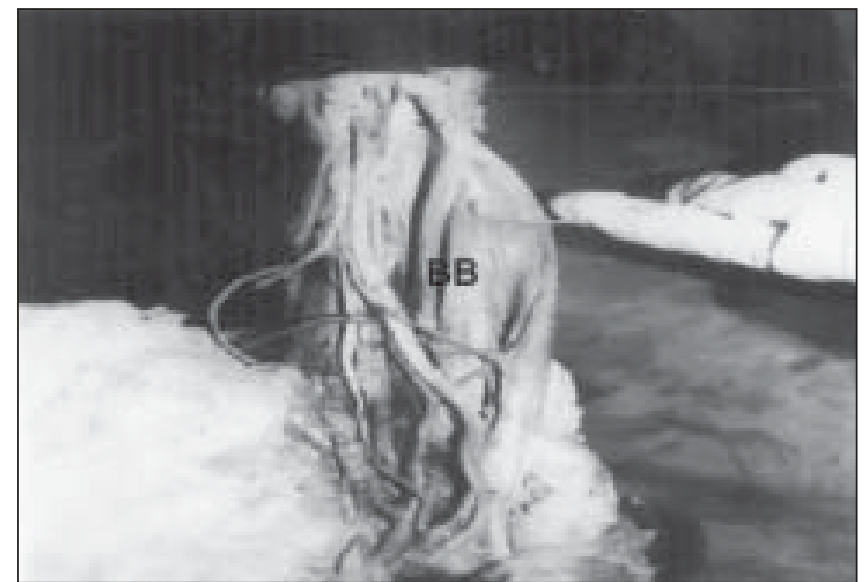

Figure 2: Photograph of the dissected right upper arm. Forceps is placed at the third head of the Biceps (BB).

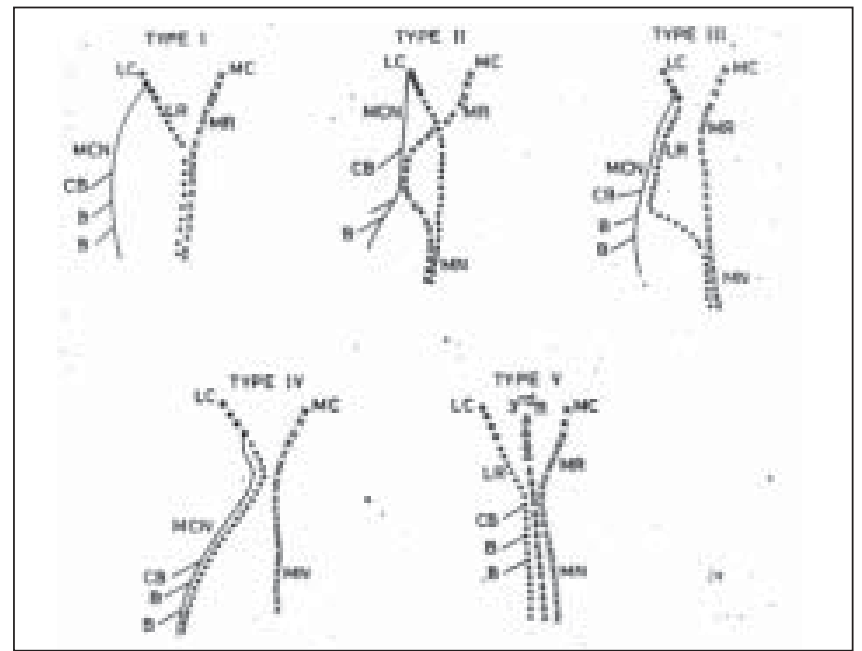

Figure 3: Figure shows variation types of Lee Minor's Classification. (LR) Lateral root of the median nerve; (MR) Medial root of median nerve; (MCN) musculocutaneous nerve; (CB) Coracobrachialis muscle; (BB) Biceps brachii; Brachialis (BR).

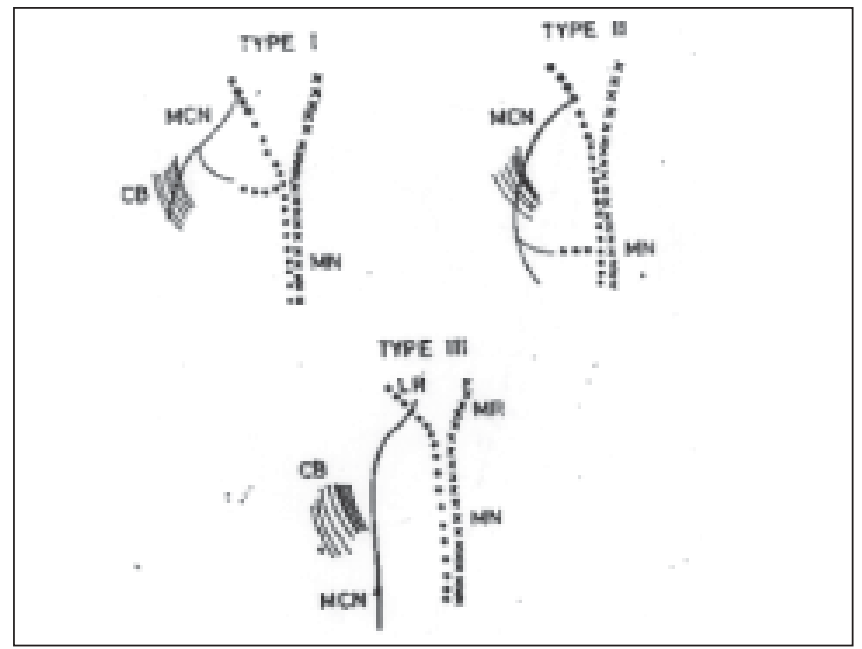

Figure 4: Figure shows various types of the Venieratos classification. (CB) Corachobrachialis muscle; (MCN) musculocutasneous nerve; (MN) Median nerve. 
Venieratos and Anagnostopoulou (1998) ${ }^{7}$ also described three different types of communication between Musculocutaneous and Median nerve in relation to Coracobrachialis [Figure 4]

Type 1: communication between Musculocutaneous and Median nerve is proximal to the entrance of Musculocutaneous into Coracobrachialis.

Type 2: communication between the two nerves is distal to the muscle.

Type 3: neither the nerve nor its communicating branch pierced the muscle.

In our study the absence of Musculocutaneous nerve was observed which coincided with type 5 of Lee Minor but did not coincide with any of Venieratos's classification. Apart from this some others have reported different kinds of variations regarding the course of these nerves. Lang Tand Spinner M $(1970)^{8}$ reported a complete fusion of the Median and Musculocutaneous nerve in one case report. Two cases of fusion of Musculocutaneous and Median nerve were found. ${ }^{9}$ Whereas in our case we found that in the right upper limb of a female cadaver the median nerve had three roots and the Musculocutaneous nerve was absent. The Median nerve innervated the arm muscles i.e. Biceps Brachii, Brachialis and Coracobrachialis. Also in the same arm we found a third head of Biceps. The accessory Biceps head originated from the anteromedial surface of the humerus, which was present in the sulcus between long and short heads and joined the two heads for insertion into the radial tuberosity. In the literature single case reports for the existence of accessory head of Biceps are there. ${ }^{10,11,12}$ but no one has reported this finding coexisting with absence of musculocutaneous nerve. The existence of this variation described in our case report may be attributed to the random factors influencing the mechanism of formation of limb muscles and the peripheral nerves during embryonic life. As it is known that the limb muscles develop from the mesenchyme of seemingly local origin, ${ }^{13}$ while the axons of the spinal nerves grow distally to reach the muscles or skin. The lack of coordination between these two processes may lead to variations. Good knowledge of possible communication between musculocutaneous and the median nerves may provide valuable in the traumatology of shoulder joint ${ }^{14}$ as well as in relations to repair operations. ${ }^{15,16}$ Although the long and short heads of Biceps Brachii are not suitable coverage of soft tissue defects in the arm, accessory heads would be indeed useful in procedures of plastic surgery. In diagnostic clinical neurophysiology variations in connections between Median and Musculocutaneous may have some significance.

\section{ACKNOWLEDGMENTS}

We acknowledge the guidance of Dr. T.S. Roy (Dept of Anatomy, A.I.I.M.S.) in writing this manuscript. We are thankful to Dr. A Shariff and Dr. B. Roy (Dept of Anatomy, A.I.I.M.S. )

\section{REFERENCES}

1. Ken AT. The brachial plexus of nerves in man. The variation in its formation and branches. American Journal of Anatomy 1918; 23 : 285-395.

2. Poynter CWM, Congenital anomalies of the arteries and veinsof human body with bibliography. University studies. University of Nebraska. 1920;22:1-106.

3. Linell EA. The distribution of nerves in the upper limb with reference to variabilities and their clinical significance. Journal of anatomy. 1921; 55: 79-112.

4. Tountas $C$ Bergaman R. Anatomic variation of the upper extremity. Churchill Livingstone, 1993; pp 223-224.

5. Williams PL, Warwick R, M Dyson M, Bamnister LH. Greys anatomy, $37^{\text {th }}$ ed. Edingburgh 1989: Churchill Livingstone, pp614615.

6. Le Minor JM. A rare variant of the median and musculocutaneous nerves in man. Archieves Anatomy Histology Embryology 1992; 73: 33-42.

7. Venierators $D$ and Anangnastopoulou $S$ classification of communication between the musculocutaneous and median nerves. Clincal Anatomy. 1998; 11: 327-331.

8. Lang T and Spinner M. An imported variation of the brachial plexus: Complete fusion of mdian and musculocutaneous nerves. 1970; Bull Hosp Jt Dis 31:7-13.

9. Watanabe $\mathrm{M}$, Tabatsuji $\mathrm{K}$, Sabamato $\mathrm{M}$, Morita $\mathrm{M}$ and Itoh $\mathrm{H}$. Two cases of fusion of the musculocutaneous and median nerves. Kaibogaki Jasshi. 1985;60:1-7.

10. Asvat $R$, Candler $P$ and Sarmiiento EE. High incidence of the third head of biceps brachii in South African population. J Anat. 1993;182:101-4.

11. Ozan H, Atsev A, Sianau a, Simsek C, Basar R. an unusual insertion of accessory biceps brachii muscle. Am Anat Nippon. 1997;72:515-9.

12. Kopuz C, Sancak B and Ozbenli, S on the incidence of third head of biceps brachii in Turkish neonates and adults. Am Anat Nippon. 1999;74:301-5.

13. Arey B. Deveolpmental anatomy $7^{\text {th }}$ ed. Philadelphia, London: WB Saunders, 1974 pp 429-35.

14. Seradge $\mathrm{H}$ and Orme $\mathrm{G}$. Acute irreducible anterior dislocation of the shoulder. J Trauma. 1920;22:330-2.

15. Benjamin AD, Hirschowitz GP, Arden and N. Blackburn. Doppelosteotamie am schutterelgenk. Orthopedic. 1981;10:245249.

16. Ha'eri GB and Wiley AM. Shoulder impingement syndrome results of operative release. Clin Orthop 1982;168:128-132. 